\title{
Copper Aluminum Mixed Oxide (CuAl MO) Catalyst: A Green approach for the One-pot Synthesis of Imines under Solvent-free Conditions
}

\author{
Madhavi N. Pahalagedara ${ }^{\dagger}$ Lakshitha R. Pahalagedara ${ }^{\dagger}$, David Kriz ${ }^{\dagger}$, Sheng-Yu Chen ${ }^{\dagger}$, Forrest \\ Beaulieu $^{\dagger}$, Wimalika Thalgaspitiya ${ }^{\dagger}$, and Steven L. Suib ${ }^{\dagger,+* *}$ \\ ${ }^{\dagger}$ De part ment of Chemistry, Univer sity of Connecticut, U-3060, 55 North Eagl eville Rd., St orr s, \\ Connect icut 06269 (USA), Fax: (+1) (860)-486-2981, E-ma il : st even.suib@uconn.edu.
}

Inst it ute of Mater ial s Science, University of Connect icut, U-3060, 55 North Eagl eville Rd., St orrs, Connect icut 06269 (USA)

\begin{abstract}
Activated carbon templated Copper Aluminum mixed oxide ( $\mathrm{CuAl} \mathrm{MO})$ catalysts have been synthesized and studied for direct imine formation by oxidative coupling of alcohols and amines under solvent free conditions. Among the catalysts, $\mathrm{CuAl} \mathrm{MO}_{20 \% \mathrm{C}}$ (catalyst synthesized by adding $20 \%$ activated carbon) shows the best activity and selectivity for this reaction. Here, air is used as the oxidant which is considered as the most economical and green oxidant among different oxidizing agents. Pyridine adsorption results confirmed that the presence of higher number of Lewis acidic sites enhances the catalytic activity of the material. Various alcohol and amine substrates were readily converted into the corresponding imines in good to excellent yields. According to catalytic activity studies and TG-MS data, surface oxygen availability and facile reversibility of oxygen readsorption on the surface account for the superior activity and high durability of the $\mathrm{CuAl} \mathrm{MO}_{20 \% \mathrm{C}}$ catalyst. The regenerated catalyst showed $92 \%$ conversion with $100 \%$ selectivity even after the $4^{\text {th }}$ reuse.
\end{abstract}


KEYWORDS: imine formation, solvent free, heterogeneous catalysis, one-pot synthesis, surface oxygen availability

\section{INTRODUCTION}

The search for new environmentally benign reagents and catalysts with high efficiency and minimum waste production has become one of the most important goals in chemistry. In this sense one-pot, tandem, or cascade reactions involving multiple catalytic transformations reduces the number of synthetic steps by leading sequential catalytic processes into one-synthetic operation with minimum workup, or change in conditions. ${ }^{1}$ These processes have become an important area of research since they improve atom economy and decrease energy consumption and raw materials consumption by avoiding intermediate separation and purification steps. ${ }^{2}$ Catalysis of two or more mechanically distinct processes by a single catalyst is known as auto tandem catalysis. Searching for such direct synthetic pathways are key for green and sustainable chemistry as they avoid side product formation, loss of starting material, separation and purification of intermediates therefore producing an economical as well as environmental benefits. $^{3,4}$

Synthesis of imines is a very important reaction in chemistry as well as in biology as they are crucial intermediates in the synthesis of biologically active nitrogen compounds, nitrogen heterocycles, fine chemicals, and pharmaceuticals. ${ }^{5,6}$ In general, imines are synthesized by the condensation of primary amines with carbonyl compounds. However, several other synthetic strategies have been developed such as dimerization of primary amines under oxidative conditions, transition metal-promoted hydrogen transfer from secondary amines, oxidation of 
secondary amines, and the direct reaction of nitro arenes and primary alcohols in the presence of hetero bimetallic catalysts. ${ }^{7,89}$

The synthesis of imines through the cross-coupling between amines and alcohols is a very useful and appropriate preparation method due to their wide substrate scope. In this method, aldehydes and ketones are obtained from alcohols by stoichiometric oxidation. Compared to carbonyl compounds, alcohols are less toxic, readily available, more stable, inexpensive, and easier to handle and produce only hydrogen or water as a byproduct. ${ }^{10}$ Therefore this is an environmentally attractive method for the synthesis of imines. Several catalytic systems have been reported for this reaction sequence based on precious metals such as platinum, iridium, and palladium under homogeneous conditions ${ }^{11,12,13}$ or other systems like graphene oxide ${ }^{14}$ and copper. ${ }^{15}$ But the pricing, limited availability, toxicities, and non-recoverable nature have forbidden their large-scale usage. ${ }^{5,16,17}$ Therefore it is highly desirable to develop mild, efficient, more environmentally and economically friendly alternatives for the synthesis of imines. ${ }^{18,19}$ Furthermore, these processes require dehydrating agents, additional bases, activated aldehydes, prolonged reaction time, high temperatures, and stoichiometric oxidants. ${ }^{20}$ However, the use of oxidants such as chromate, permanganate or 2-iodoxybenzoic acid ${ }^{21}$ has several drawbacks, which are the difficulty in product separation and the formation of undesirable toxic waste products.

Mixed metal oxides that contain transition metals can play a significant catalytic role in a large variety of heterogeneous chemical processes. Among them $\mathrm{Cu}$ and $\mathrm{Al}$ based oxides can be considered as potential catalysts as they are relatively cheap and can readily be prepared by diverse synthetic routes. Moreover, it has been put forward that the presence of acidic sites is very important for these types of reactions and mixed oxides show much stronger acidic 
properties compared to single oxides. In the present study, we report the tandem synthesis of imines directly from alcohols and amines under mild conditions using an inexpensive $\mathrm{CuAl}$ mixed oxide (MO) catalyst and air as an oxidant. $\mathrm{CuAl} \mathrm{MO}$ acts as a bifunctional catalyst in the process to oxidize the alcohol to the corresponding carbonyl compound and then acts as a Lewis acid to form the imine. Here, the $\mathrm{CuAl}$ mixed hydroxide material was precipitated from a homogeneous solution of metal salts by the thermally induced hydrolysis of urea. Then the mixed hydroxide has been converted into the metal oxide by thermal treatment. The synthesis was performed in the presence of activated carbon which subsequently helps to tune the surface properties of the resultant metal oxide. The catalytic process is done under solvent free conditions and does not form any harmful byproducts. In this reaction, air is used as the oxidant which is considered as the most economical and green oxidant among different oxidizing agents. Furthermore, no base additives, dehydrating agents, or any special apparatus are needed.

\section{EXPERIMENTAL SECTION}

\subsection{Synthesis of activated carbon/mixed hydroxide composites and corresponding metal oxide catalysts}

Activated carbon was purchased from Calgon Carbon Corporation. Activated carbon/CuAl mixed hydroxide composite $(\mathrm{Cu} / \mathrm{Al}$ molar ratio $=3)$ was synthesized through a urea hydrolysis process in the presence of activated carbon. Synthesis was done by adding $1.5 \times 10^{-3} \mathrm{~mol}$ of $\mathrm{Cu}\left(\mathrm{NO}_{3}\right)_{2} \cdot 6 \mathrm{H}_{2} \mathrm{O}, 0.5 \times 10^{-3} \mathrm{~mol}$ of $\mathrm{Al}\left(\mathrm{NO}_{3}\right)_{3} \cdot 9 \mathrm{H}_{2} \mathrm{O}, 4.0 \times 10^{-3} \mathrm{~mol}$ of urea and a known amount of activated carbon into $60 \mathrm{~mL}$ deionized water under vigorous stirring at room temperature. The mixture was refluxed at $100^{\circ} \mathrm{C}$ for $15 \mathrm{~h}$ and the final $\mathrm{pH}$ of the solution was about 10 . Then, the obtained dark green colored mixture was filtered and washed with deionized water for several 
times. The resultant dark green colored solid was then dried under vacuum at $60^{\circ} \mathrm{C}$ for $12 \mathrm{~h}$ and calcined in a furnace at $500^{\circ} \mathrm{C}$ for $3 \mathrm{~h}$ in air in order to remove activated carbon. The entire procedure was repeated, changing the amount of activated carbon $(5 \%, 10 \%$ and $20 \%-\% \mathrm{w} / \mathrm{w})$ added while keeping other reaction conditions constant, to obtain a series of activated carbon/ mixed hydroxide composites. Controlled experiments were also carried out by repeating the whole process in the absence of activated carbon. The obtained calcined materials were denoted as $\mathrm{CuAl} \mathrm{MO}_{\mathrm{x} \% \mathrm{C}}(\mathrm{x}=0,5,10,20)$ where $\mathrm{x}$ stands for the activated carbon amount.

\subsection{Catalyst characterization}

Powder X-ray diffraction (XRD) analyses were performed on a Rigaku Ultima IV diffractometer with $\mathrm{Cu} \operatorname{K\alpha }(\lambda=0.15406 \mathrm{~nm})$ radiation with a beam voltage of $40 \mathrm{kV}$ and a beam current of 44 $\mathrm{mA}$. Continuous scans were taken in a $2 \theta$ range of $5-60^{\circ}$ with a scanning rate of $2.0^{\circ} / \mathrm{min}$, and the phases were identified using the International Center for Diffraction Data (ICDD) database. Surface morphologies of the synthesized materials were studied using field emission scanning electron microscopy (FE-SEM) on a Zeiss DSM 982 Gemini instrument with a Schottky emitter at an accelerating voltage of $2.0 \mathrm{kV}$ with a beam current of $1.0 \mathrm{~mA}$. The samples were ultrasonically suspended in absolute ethanol and dispersed on Au-coated silicon chips and then dried overnight under vacuum. The EDX analysis was done using an Oxford X-max 80 EDX analyzer operat ing at an el ectron accel erat ing vol tage of $10 \mathrm{kV}$.

Transmission electron microscopy (TEM) was used to examine the surface morphologies and the crystalline structures of the materials using a JEOL 2010 instrument with an accelerating voltage 
of $200 \mathrm{kV}$. The samples were prepared by dispersing the material in ethanol. Then a drop of the dispersion was placed on a carbon coated copper grid and allowed to dry before analysis.

The nitrogen sorption experiments were performed using a Quantachrome Autosorb $\mathrm{iQ}_{2}$ instrument instrument using $\mathrm{N}_{2}$ gas as the adsorbate at $77 \mathrm{~K}$ by a multipoint method. The Brunauer- Emmett-Teller (BET) method was used to determine the specific surface area and the Barrett-Joyner-Halenda (BJH) desorption method was used to calculate the pore size distribution and pore volume. Prior to the analysis, all the samples were degassed at $150^{\circ} \mathrm{C}$ for $12 \mathrm{~h}$ in order to remove any adsorbed species.

Fourier transform infrared (FTIR) spectroscopy experiments were performed using a ThermoScientific Nicolet FT-IR Model 8700 (in the range $4000-400 \mathrm{~cm}^{-1}$ ) equipped with a DTGS detector and a $\mathrm{KBr}$ beam splitter. Spectra were collected with a resolution of $4 \mathrm{~cm}^{-1}$ using 250 scans. Pyridine adsorption studies were performed with $13 \mathrm{~mm}$ diameter self-supporting pellets. The pellets were cleaned in a tubular furnace at $250^{\circ} \mathrm{C}$ for $2 \mathrm{~h}$ under dry air flow. A $1 \mathrm{M}$ pyridine solution in methanol was dropped on pellets, and physisorbed pyridine was removed in a tubular furnace running at $200^{\circ} \mathrm{C}$ for 90 min under dry air flow and FTIR spectra of the pellets were collected. $^{22}$

Thermogravimetric mass spectrometry (TG-MS) was studied using a Netzsch Libra TG209 F1 thermogravimetric analyzer coupled to a Netzsch Aëolos QMS 403C quadrupole mass spectrometer. Approximately $15 \mathrm{mg}$ of sample was loaded into an alumina crucible. Argon was flowed through the sample chamber at $50 \mathrm{SCCM}$ while the temperature was ramped from room temperature to $1000^{\circ} \mathrm{C}$ at a rate of $20^{\circ} \mathrm{C} / \mathrm{min}$.

X-ray photoelectron spectroscopy (XPS) was done on a PHI model 590 spectrometer with multiprobes (ФPhysical Electronics Industries Inc.), using Al K radiation $(\lambda=1486.6 \mathrm{eV})$ as the 
radiation source and was fitted using CasaXPS software (version 2.3.12). The powder samples were pressed onto carbon tape mounted on adhesive copper tape stuck to a sample stage placed in the analysis chamber. For correction of surface charging, the C 1s photoelectron line at 284.6 $\mathrm{eV}$ was taken as a reference.

\subsection{Catalytic activity: One-Pot coupling of 4-Chlorobenzyl alcohol and Benzylamine}

For catalytic studies, one-pot coupling of 4-Chlorobenzyl alcohol and Benzylamine was carried out in a batch reactor. 4-Chlorobenzyl alcohol and Benzylamine were purchased from SigmaAldrich and used without further purification. A mixture of $1 \mathrm{mmol}$ of 4-Chlorobenzyl alcohol, $1.2 \mathrm{mmol}$ of Benzylamine, and $50 \mathrm{mg}$ of catalyst were stirred under solvent free conditions in a 5 $\mathrm{mL}$ round bottom flask and the reaction was conducted at $110^{\circ} \mathrm{C}$ for $12 \mathrm{~h}$ in an oil bath under air atmosphere.

The spent catalyst was recovered by centrifuging the reaction mixture, washing with ethanol and drying in an oven at $120^{\circ} \mathrm{C}$ for $12 \mathrm{~h}$. The gas chromatography-mass spectroscopy (GC-MS) method was used for the quantitative analysis and identification of the reaction product. Analyses were performed using a HP 5971 mass selective detector coupled to a HP 5890 Series II gas chromatograph equipped with a thermal conductivity detector (TCD) through an HP-1 (nonpolar cross-linked methyl siloxane) column with dimensions of $12.5 \mathrm{~m} \times 0.2 \mathrm{~mm} \times 0.33 \mu \mathrm{m}$. 


\section{RESULTS}

\subsection{Structural characterization of activated carbon/mixed hydroxide composites and corresponding metal oxides}

XRD patterns of as synthesized $\mathrm{CuAl}-\mathrm{C}_{\mathrm{x} \%}$ mixed hydroxide materials are displayed in Figure $\mathrm{S} 1$. Samples synthesized with $0 \%, 5 \%$ and $10 \%$ activated carbon showed a $\mathrm{CuAl}$ mixed hydroxide phase while the XRD pattern of the sample with $20 \%$ activated carbon corresponded to a copper nitrate hydroxide phase (ICDD 75-1779). Activated carbon acts as a template and it remains as a separate phase in all the compositions. However, above $20 \%$, some inhomogeneity appears in the reaction mixture; therefore the product obtained was not taken into consideration. When these materials were calcined to remove the template, the hydroxide phase is converted to the oxide phase and XRD peaks could be indexed to the tenorite $\mathrm{CuO}$ phase (Figure 1) (ICDD 80-1916).

The average crystallite sizes of calcined samples were calculated according to the Debye Scherrer equation, $L=K \lambda / \beta(\theta) \cos \theta$ where $L$ is the crystallite size, $K$ is the crystallite shape factor $(0.89), \lambda$ is the wavelength of the radiation used $(0.15406 \mathrm{~nm}), \theta$ is the Bragg diffraction angle, and $\beta(\theta)$ is the full width at half maximum. Oxide material synthesized without any carbon gave the highest crystallite size which was $27.7 \mathrm{~nm}$. When activated carbon was incorporated to the structure, a huge drop in crystallite size was observed (Table 1). 20\% sample gave the smallest crystallite size among the series which was $1.1 \mathrm{~nm}$.

Porous MOs obtained by calcining the samples at $500^{\circ} \mathrm{C}$ were analyzed by $\mathrm{N}_{2}$ sorption measurements to study their textural properties and pore size distributions. $\mathrm{N}_{2}$ adsorption/desorption isotherms and $\mathrm{BJH}$ pore size distributions of the obtained MOs are presented in Figures $2 \mathrm{a}$ and $2 \mathrm{~b}$. All samples have a Type IV $\mathrm{N}_{2}$ adsorption isotherm along with a Type I hysteresis loop, indicating a regular cylindrical mesoporous structure (Figure 2a). CuAl 
$\mathrm{MO}_{20 \% \mathrm{C}}$ sample gave the highest BET surface area $\left(161 \mathrm{~m}^{2} / \mathrm{g}\right)$, highest pore diameter $(40 \AA)$ and the highest pore volume $\left(0.27 \mathrm{~cm}^{3} / \mathrm{g}\right)$ among the compositions tested. Increasing the amount of activated carbon leads to an increase in the surface area and pore volume. Specific surface area values and pore parameters of $\mathrm{CuAl}$ MOs are given in Table 1. The $\mathrm{CuAl} \mathrm{MO}_{20 \% \mathrm{C}}$ sample has a larger $\mathrm{N}_{2}$ uptake than other samples, which indicates a higher mesopore volume than other MO samples (Figure 2a). All the samples display a late adsorption edge $(\mathrm{P} / \mathrm{P} 0>0.8)$ suggesting an increase in pore size. $\mathrm{BJH}$ desorption pore diameters of all the samples lie in the same range and $\mathrm{CuAl} \mathrm{MO}_{20 \% \mathrm{C}}$ sample gave a uniform pore size distribution compared to other samples.

The surface morphology of mixed hydroxide samples and CuAl MO samples was observed by FE-SEM. As clearly observed in Figure 3a, mixed hydroxide material synthesized in the absence of activated carbon template shows a rough plate like morphology. In contrast, the material prepared with $20 \%$ activated carbon, exhibits a nice flower like nanostructure (Figure $3 b$ ). Upon heat treatment, all the materials are converted to the MO and FE-SEM images of the CuAl MO samples synthesized with different amounts of activated carbon are given in Figure $3 \mathrm{c}$ and Figure S2. When increasing the amount of activated carbon, the surface of the material changes from an irregular shaped plate-like morphology to a nicely arranged flower-like morphology. In all MO samples, $\mathrm{Cu}$ and $\mathrm{Al}$ are uniformly dispersed and can be detected in all zones measured in a constant composition ( $\mathrm{Cu} 21 \%$, Al $23 \%$, O 56 \% EDS measured). FESEM-EDX elemental maps for $\mathrm{Cu}, \mathrm{Al}$, and $\mathrm{O}$ in the $\mathrm{CuAl} \mathrm{MO}_{20 \% \mathrm{C}}$ catalyst are given in Figure $\mathrm{S} 3$. According to the TEM image of $\mathrm{CuAl} \mathrm{MO}_{20 \% \mathrm{C}}$ catalyst given in Figure $\mathrm{S} 4$, the material is composed of ovalshaped crystalline nanosized particles where the width of a particle is around $30 \mathrm{~nm}$ and the length of a particle is around $50 \mathrm{~nm}$. 
The FTIR spectra of the as synthesized mixed hydroxide material $(20 \% \mathrm{C})$ and the $\mathrm{CuAl} \mathrm{MO}_{20 \% \mathrm{C}}$ catalyst are given in Figure S5. Mixed hydroxide material gives a broad band between 3400 and $3600 \mathrm{~cm}^{-1}$ due to the stretching modes of $\mathrm{OH}$ groups. ${ }^{23,24}$ The presence of $\mathrm{NO}_{3}{ }^{-}$in the as-prepared samples is evidenced by the vibrational bands that occurred from middle to lower wavenumbers, suggesting the presence of mono- or polydentate nitrate ligands $(1432,1376,1320,1348$, and $\left.802 \mathrm{~cm}^{-1}\right){ }^{25}$ However, after heat treatment (Figure S5b), peaks at $3400-3600 \mathrm{~cm}^{-1}$ and at 802 $1432 \mathrm{~cm}^{-1}$ were completely disappeared. This means that all the nitrate groups and hydroxyl groups were removed after the heat treatment of the mixed hydroxide phase in air at $500^{\circ} \mathrm{C}$. The bands below $700 \mathrm{~cm}^{-1}$ are attributed to the framework vibrations of mixed oxide material. ${ }^{26,27}$ To rationalize the catalyst effects, the surface acidity was studied by pyridine adsorption experiments as imine formation from carbonyls is generally acid catalyzed. The obtained profiles are presented in Figure 4. These FTIR spectra show pyridine adsorbed $\mathrm{CuAl} \mathrm{MO}_{0 \% \mathrm{C}}, \mathrm{CuAl}$ $\mathrm{MO}_{5 \% \mathrm{C}}$ and $\mathrm{CuAl} \mathrm{MO}_{20 \% \mathrm{C}}$ samples in the region between $1400-1500 \mathrm{~cm}^{-1} . \mathrm{CuAl} \mathrm{MO}_{0 \% \mathrm{C}}$ sample did not show any detectable peaks. However, the other two samples $\left(\mathrm{CuAl} \mathrm{MO}_{5 \% \mathrm{C}}\right.$ and $\mathrm{CuAl} \mathrm{MO}_{20 \% \mathrm{C}}$ ) gave three peaks at around 1450, 1490, and $1538 \mathrm{~cm}^{-1}$. The intensities of the peaks are greatly enhanced when going from the $5 \% \mathrm{C}$ sample to the $20 \% \mathrm{C}$ sample (Figure 4 b,c). In the figure, pyridine adsorbed on Brønsted acid sites is labelled as B and pyridine adsorbed on Lewis acid sites is labelled as $\mathrm{L}$.

The thermogravimetric mass spectrometry (TG-MS) analysis profiles of $\mathrm{CuAl} \mathrm{MO}_{0 \% \mathrm{C}}, \mathrm{CuAl}$ $\mathrm{MO}_{5 \% \mathrm{C}}$ and $\mathrm{CuAl} \mathrm{MO}_{20 \% \mathrm{C}}$ samples are shown in Figure 5. When $\mathrm{CuAl} \mathrm{MO}_{0 \% \mathrm{C}}$ material was heated, the TG curve revealed weight losses in four stages. The first weight loss was observed between 100 and $220^{\circ} \mathrm{C}$, second weight loss between 220 and $330^{\circ} \mathrm{C}$, and two weight losses 
between 350 and $600^{\circ} \mathrm{C}$ and beyond $700^{\circ} \mathrm{C}$. Compared to $\mathrm{CuAl} \mathrm{MO}{ }_{0 \% \mathrm{C}}, \mathrm{CuAl} \mathrm{MO}_{5 \% \mathrm{C}}$ and $\mathrm{CuAl}$ $\mathrm{MO}_{20 \% \mathrm{C}}$ samples gave only two weight losses between 100 and $220^{\circ} \mathrm{C}$ and beyond $700^{\circ} \mathrm{C}$.

In its $\mathrm{O}_{2}$ evolution profile, $\mathrm{CuAl} \mathrm{MO}_{0 \% \mathrm{C}}$ shows three peaks between 220 and $330^{\circ} \mathrm{C}, 350$ and $600^{\circ} \mathrm{C}$ and beyond $700^{\circ} \mathrm{C}$. On the other hand, $\mathrm{CuAl} \mathrm{MO}_{20 \% \mathrm{C}}$ evolves $\mathrm{O}_{2}$ from room temperature to $400^{\circ} \mathrm{C}$ and beyond $700^{\circ} \mathrm{C}$.

XPS studies were done in order to investigate the oxidation states of $\mathrm{Cu}$ in the catalyst. The spectrum (Figure S6) presents the diagnostic shake-up peaks of $\mathrm{CuO}$ and the peaks of $\mathrm{Cu} 2 \mathrm{p}_{3 / 2}$ and $\mathrm{Cu} 2 \mathrm{p}_{1 / 2}$, indicating copper (II) oxide. The shakeup satellites are characteristic of materials having a $\mathrm{d} 9$ configuration in the ground state, i.e., $\mathrm{Cu}^{2+}$."

\subsection{Catalytic activity}

The intial imine synthesis was performed using 4-Chlorobenzyl alcohol and benzyl amine at 110 ${ }^{\circ} \mathrm{C}$ in the presence of air and the results are given in Table 2. All the reactions were carried out with $\mathrm{CuAl} \mathrm{MO}$ samples under solvent free conditions. Among the various catalysts tested, $\mathrm{CuAl}$ $\mathrm{MO}_{20 \% \mathrm{C}}$ showed the best activity over others. The conversion was $95 \%$ in 6 hours, and the imine was the only product giving a $100 \%$ selectivity. Other catalysts synthesized in the presence of activated carbon similarly gave an impressive conversion. The material synthesized without activated carbon gave a low conversion compared to carbon templated catalysts (Table 2, entry 1). Commercial $\mathrm{CuO}$ and $\mathrm{CuAl}_{2} \mathrm{O}_{4}$ could only give the imine product with conversions of $8 \%$ and $2 \%$, respectively.

After confirming $\mathrm{CuAl} \mathrm{MO}_{20 \% \mathrm{C}}$ as the most effective catalyst, the reaction conditions were further optimized. The reaction was carried out at different temperatures to investigate the effect of temperature on the catalytic performance, and the results are given in Table 2 (entries 6-8). 
The percentage of conversion surged along with increasing reaction temperature from $18 \%$ at $60^{\circ} \mathrm{C}$ to $95 \%$ at $110^{\circ} \mathrm{C}$ with $100 \%$ selectivity for the imine product. Any further increase in the temperature decreases conversion of the reaction.

In order to confirm the effect of oxidant, which is air in this case, the reaction was performed under inert $\left(\mathrm{N}_{2}\right)$ atmosphere in the presence of the catalyst. According to the results, the reaction gave only $15 \%$ conversion without air. However, the blank experiment carried out with air in the absence of catalyst showed no conversion (Table 2, entry 10).

\subsection{Reaction scope}

Based on these results, the scope and limitations of $\mathrm{CuAl} \mathrm{MO}_{20 \% \mathrm{C}}$ catalyzed imine synthesis were explored using various structurally diverse amines and alcohols. First, various amines were tested with 4-Chlorobenzyl alcohol as the coupling partner (Table 3). Reaction rate was faster when butyl amine was used as the amine, giving $99 \%$ conversion with $100 \%$ selectivity in 6 h. 4 Chlorobenzylamine, 2, 4-Dichlorobenzylamine and 4-Methoxybenzylamine gave 82\%, 74\% and $91 \%$ conversions under the same reaction conditions (entries $2,3, \& 4)$. When the reaction was carried out with aniline, the conversion was only $64 \%$; however the selectivity for imine was still $100 \%$.

Next, the reactions between benzylamine and different alcohols were tested. 4-chlorobenzyl alcohol with benzylamine (entry 6) gave $95 \%$ conversion and $100 \%$ selectivity for imine. 4 methoxy benzylalcohol (entry 7) gave $70 \%$ conversion and $100 \%$ selectivity for the corresponding imine. In contrast, when 3,4-Dimethoxy benzylalcohol was reacted the conversion was only $67 \%$ and selectivity was $84 \%$ (entry 8 ). 2-propanol (entry 9) gave the lowest 
conversion among the series which was $22 \%$ but the selectivity was still $100 \%$. The desired imine was obtained as the major product during the whole course of the reaction.

In order to determine the role of the catalyst in the formation of the aldehyde in the first step and formation of imine in the second step, a series of reactions were carried out and the results are given in Table 3. When 4-Chlorobenzyl alcohol was reacted with 2,4- Dichlorobenzylamine in the absence of the catalyst, a trace amount of the imine product was observed with a $100 \%$ selectivity (entry 10). When the reaction was started with 4-Chlorobenzaldehyde (entry 11, 12), $88 \%$ and $52 \%$ conversions were observed with and without the catalyst respectively.

The reusability was tested by recycling the spent catalyst in consecutive runs. The catalyst was recovered by centrifuging the reaction mixture, washing with acetone and water and then drying at $200^{\circ} \mathrm{C}$ for $12 \mathrm{~h}$. The regenerated catalyst exhibited only a slight catalytic activity loss compared to the fresh catalyst ( $100 \%$ conversion, $100 \%$ selectivity) even after the $4^{\text {th }}$ reuse $(92 \%$ conversion, 100\% selectivity) (Figure S7). XRD patterns and SEM images of the catalyst before and after the reaction are given in Figures S8 and S9. According to Figure S8, the recovered catalyst exhibited the same crystal structure as the fresh catalyst however intensities of the peaks have been decreased. The XRD pattern of the catalyst after the reaction under $\mathrm{N}_{2}$ atmosphere is given in Figure S10. All the characteristic peaks of the CuAl MO catalyst are present. Apart from that, 3 peaks with relatively high intensity were observed at about $43.30^{\circ}, 50.41^{\circ}$, and $74.10^{\circ}$ which can be attributed to the $\mathrm{Cu}(0)$ state.

\section{DISCUSSION}


The application of highly abundant, relatively cheap carbon materials as hard templates has been widely used to synthesize structurally ordered materials with enhanced performances. ${ }^{28-31}$ In the current study, activated carbon has been used to alter surface properties of the material and acts as an efficient green catalyst for the synthesis of imines under solvent free conditions. Here, synthesis of mixed metal hydroxide/carbon composite has been achieved through coprecipitation under refluxing conditions from the metal salt solution, urea, and activated carbon. The carbon template is removed by thermal treatment in order to obtain the corresponding metal oxide material. In this method, the carbon surface defects and active sites function as nucleation centers for the growth of metal hydroxide crystallites during synthesis. ${ }^{31}$ The crystal and surface structures of the final material (crystallinity, surface area, pore volume, pore diameter) can be modified by adjusting the activated carbon amount in the initial reaction mixture.

$\mathrm{N}_{2}$ sorption analysis was used to compare the surface properties of materials synthesized in the presence and in the absence of activated carbon template. The $\mathrm{CuAl} \mathrm{MO}_{20 \% \mathrm{C}}$ material has the highest specific surface area, pore volume, and pore diameter among the series. In this case, activated carbon functions as a mold to cast the product and the structure obtained is reciprocal to that of the template. Pore parameters of the template will eventually direct the particle size and pore structure of the final material. ${ }^{29}$ According to the current study, the amount of the template has also played a crucial role in determining the surface properties of the final product.

$\mathrm{CuAl} \mathrm{MO}_{20 \% \mathrm{C}}$ material showed the highest catalytic activity for the synthesis of imines. The surface properties and surface acidity studies might help to understand the differences in catalytic performance. ${ }^{32}$ The superior catalytic activity of $\mathrm{CuAl} \mathrm{MO}_{20 \% \mathrm{C}}$ material may be associated with its surface properties. ${ }^{33}$ According to FE-SEM images, CuAl MO material synthesized without the carbon template consisted of irregular shaped clusters of particles. 
However, the $\mathrm{CuAl} \mathrm{MO}_{20 \% \mathrm{C}}$ sample is composed of a more uniform and organized flower-like microstructure compared to all the other samples. Moreover, the average crystallite size of the catalyst has been decreased upon increasing the activated carbon amount and $\mathrm{CuAl} \mathrm{MO}_{20 \% \mathrm{C}}$ material which has the smallest crystallite size in the series exhibited the highest activity. The unique surface morphology, high surface area, additional porosity and uniform pore size distribution help in diffusion and transportation of reactant molecules in the mesoporous network and may be the reason for the enhanced activity. ${ }^{34}$

According to the results obtained, the alcohol gets oxidized to form the aldehyde and then condenses with amine to form the imine product. When the reaction is done without the catalyst under atmospheric conditions, a trace amount of the product is obtained and the aldehyde product is not obtained. This confirms that the oxidation step requires the presence of the catalyst. When the reaction is done under $\mathrm{N}_{2}$, a conversion of $15 \%$ was observed and the XRD pattern of the used catalyst gives peaks corresponding to metallic $\mathrm{Cu}$. The structural oxygen has been used in the oxidation step. This confirms that the presence of the catalyst is essential to carry out the first step. The imine product was observed, when the reaction was started with the aldehyde. However, the presence of the catalyst enhances the rate of the second step, giving a higher conversion compared to the uncatalyzed reaction. This second step involves a nucleophilic attack on the in situ generated carbonyl and is generally acid catalyzed. ${ }^{35}$ The acidic nature of the $\mathrm{CuAl} \mathrm{MO}$ catalyst was determined by pyridine adsorption experiments, which are excellent techniques for the characterization of acid sites on heterogeneous solid acid catalysts. According to pyridine adsorption-FTIR spectra (Figure 4), peaks observed in the region between $1400-1550 \mathrm{~cm}^{-1}$ arise due to C-C stretching vibrations of pyridine. The peak at $1450 \mathrm{~cm}^{-1}$ can be assigned to pyridine adsorbed on Lewis acid sites; the peak at $1538 \mathrm{~cm}^{-1}$ is characteristic of 
pyridine adsorbed on Brønsted acid sites and the peak at $1490 \mathrm{~cm}^{-1}$ appears for pyridine adsorbed on both Brønsted and Lewis acid sites. It is a well-known fact that mixed oxides show much stronger acidic properties than single oxides. The enriched acidic properties of mixed oxides are considered to be the result of an excess negative or positive charge induced by the formation of non-equivalent $\mathrm{M}_{1}-\mathrm{O}-\mathrm{M}_{2}$ bonds. Moreover, adding activated carbon as a structure directing agent has significantly enhanced the surface area and the pore volume of the catalyst resulting in much superior activity as compared with the catalyst synthesized without the carbon material. The key to obtain a high conversion and a high selectivity with the $\mathrm{CuAl} \mathrm{MO}_{20 \% \mathrm{C}}$ catalyst is the lower diffusion restrictions and the presence of strong Lewis acidic sites with a higher proportion that catalyze the nucleophilic attack. ${ }^{22,36}$

When the reaction was performed under a $\mathrm{N}_{2}$ atmosphere, only $15 \%$ conversion was obtained, confirming that air was essential as the oxidant. Moreover, obtaining a trace amount of the imine in the absence of the catalyst suggests that the reaction described herein is entirely catalytic in nature. The general applicability of this catalytic system was extended to study different alcohol and amine substrates (Table 3). First, the coupling between 4-Chlorobenzyl alcohol and various amine substrates was examined. According to the results, the nucleophilicity of the amine plays a significant role in the reaction process. Propyl amine, which is a primary aliphatic amine, is more basic than other amines hence shows enhanced reactivity. The same trend was observed with 2,4Dichlorobenzylamine (Table 3 - entry $3, \mathrm{pKb}=5.28)$, 4- Chlorobenzylamine (Table 3 - entry 2 , $\mathrm{pKb}=4.86)$, and 4-Methoxybenzylamine (Table 3 - entry $4, \mathrm{pKb}=4.5$ ) where more basic amine substrates give higher conversions. The low basicity of aniline also results in a relatively low rate of nucleophilic attack on the carbonyl carbon to form the imine. ${ }^{14,37,38}$ 
All the examined alcohol substrates: 2-Propyl alcohol, benzyl alcohol, 4-Mmethoxybenzyl alcohol and 3,4-Dimethoxybenzyl alcohol were oxidized and coupled with benzylamine to produce the desired imine products (Table 3 - entry 6-9) with high selectivity. According to the obtained results, the presence of electron donating or withdrawing groups in the aromatic ring play an important role in determining the conversion. The presence of electron withdrawing groups in the para position of the aromatic alcohol results in enhanced conversion (Table 3entry 6) while the presence of electron donating groups results in lower conversion (Table 3entry 7,8$)$. Electron donating groups increase the electron density in the aromatic ring and this results in the difficulty in the oxidation process and reduced electrophilicity in the formed carbonyl. In contrast, electron withdrawing groups can enhance oxidation and electrophilicity. ${ }^{39}$ Compared to other alcohols, 2-Propyl alcohol which is an aliphatic secondary alcohol gave a very low conversion as it is difficult to oxidize to the corresponding ketone with the current catalyst.

According to the TG-MS profile of $\mathrm{CuAl} \mathrm{MO}_{0 \% \mathrm{C}}$, the weight loss between 100 and $220^{\circ} \mathrm{C}$ can be attributed to decomposition of physisorbed water and adsorbed gasses. ${ }^{40}$ The second and third weight losses occur due to evolution of surface oxygen and structural oxygen. This material showed the highest $\mathrm{O}_{2}$ evolution and contains $1.75 \%(0.28 \mathrm{mg})$ of structural oxygen according to the TG-MS profile. The final weight loss beyond $700^{\circ} \mathrm{C}$ can be attributed to the evolution of lattice oxygen. ${ }^{41}$ In contrast to that, $\mathrm{CuAl} \mathrm{MO}_{20 \% \mathrm{C}}$ catalyst shows evolution of surface oxygen starting at room temperature to $400^{\circ} \mathrm{C}$ and lattice oxygen beyond $700^{\circ} \mathrm{C}$. These data along with the catalytic data obtained with and without catalyst and XRD studies before and after the reaction under air and nitrogen atmosphere (Figure S8 and S10) collectively suggest that surface oxygen availability and facile reversibility of oxygen readsorption (Mars-van Krevelen 
mechanism) on the surface may account for the superior activity and high durability of the $\mathrm{CuAl}$ $\mathrm{MO}_{20 \% \mathrm{C}}$ catalyst. ${ }^{42,43}$

On the basis of experiments and the literature, we propose a mechanism for imine synthesis by CuAl MO catalyst. The first step involves the oxidation of the alcohol to its corresponding aldehyde or ketone. A Mars-van Krevelen type oxidation mechanism has been proposed and it suggests a multi-electron redox process (Scheme S1). The second step involves a nucleophilic attack on the generated carbonyl. Pyridine adsorption studies confirm that the catalyst has Lewis acidic sites, thus when the amine attacks the carbonyl carbon, it provides Lewis acidic sites for oxygen in order to facilitate the catalytic imine formation (Scheme S2). ${ }^{35}$ When compared to literature reported studies, this approach involves several advantages. Most reported precious metal based catalysts are significantly more expensive and non-recoverable compared to the catalyst reported in this work. Here, imine synthesis is achieved starting from alcohols and amines and air is used as the environmentally benign terminal oxidant. From a point of view of green chemistry, removing the solvent from a chemical process is one of the most important steps in the reduction (energy,waste, etc.) and simplification in the work-up as well as the reaction. This catalyst gives very high conversions and selectivities for the synthesis of imine compounds under solvent free conditions. Due to all these reasons, this can be considered as a green catalyst superior to other reported heterogeneous catalytic systems.

\section{CONCLUSIONS}

In conclusion, an efficient and a green catalytic process to synthesize imines directly from alcohols and amines using $\mathrm{CuAl}$ MO catalyst has been reported. Activated carbon has been successfully used as a template for the synthesis of $\mathrm{CuAl} \mathrm{MO}$ catalysts with modified surface 
properties. $\mathrm{CuAl} \mathrm{MO}_{20 \% \mathrm{C}}$ material exhibited a uniform pore size distribution (pore diameter 40 $\AA)$ with the highest surface area $\left(161 \mathrm{~m}^{2} / \mathrm{g}\right)$ and showed the best catalytic performance. CuAl MO catalyzes two distinct processes, oxidation followed by imine formation in a single reaction vessel under the same reaction conditions. Diverse types of substituted imines can be obtained with $100 \%$ selectivity without any base additives or precious metal catalysts. The reaction is aerobic, environmentally benign, and proceeds under solvent free conditions. The acidic nature, surface oxygen availability and facile reversibility of oxygen readsorption on the surface account for the superior activity of the catalyst. This method has versatile scope for various alcohols and amines and $\mathrm{CuAl} \mathrm{MO}$ catalyst can be reused several times without significant loss of its catalytic activity.

\section{Appendix A. Supplementary data}

X-ray diffraction patterns of $\mathrm{CuAl}$ mixed hydroxide materials synthesized with different amounts of activated carbon; FE-SEM images of $\mathrm{CuAl} \mathrm{MO}_{0 \% \mathrm{C}}, \mathrm{CuAl} \mathrm{MO}_{5 \% \mathrm{C}}$ and $\mathrm{CuAl} \mathrm{MO}_{10 \% \mathrm{C}}$ catalysts; FESEM-EDX elemental maps for $\mathrm{Cu}, \mathrm{Al}$, and $\mathrm{O}$ in the $\mathrm{CuAl} \mathrm{MO}_{20 \% \mathrm{C}}$ catalyst; TEM images of fresh $\mathrm{CuAl} \mathrm{MO}_{20 \% \mathrm{C}}$ catalyst; FTIR spectra of $\mathrm{CuAl}$ mixed hydroxide material synthesized with $20 \%$ activated carbon and $\mathrm{CuAl} \mathrm{MO}_{20 \% \mathrm{C}}$ catalyst; $\mathrm{Cu} 2 \mathrm{p}$ XPS spectrum of $\mathrm{CuAl}$ $\mathrm{MO}_{20 \% \mathrm{C}}$ catalyst; Reusability of $\mathrm{CuAl} \mathrm{MO}_{20 \% \mathrm{C}}$ catalyst in the imination reaction of 4Chlorobenzyl alcohol and benzylamine; XRD patterns of the fresh $\mathrm{CuAl} \mathrm{MO}_{20 \% \mathrm{C}}$ catalyst and the recovered catalyst; FE-SEM images of fresh $\mathrm{CuAl} \mathrm{MO}_{20 \% \mathrm{C}}$ catalyst and the recovered catalys; XRD pattern of the recovered $\mathrm{CuAl} \mathrm{MO}_{20 \% \mathrm{C}}$ catalyst (Reaction performed under $\mathrm{N}_{2}$ atmosphere); $\mathrm{N}_{2}$ adsorption/desorption isotherm and $\mathrm{BJH}$ pore size distribution curve of activated carbon; Mechanism of alcohol oxidation; Mechanism of imine synthesis. 


\section{ACKNOWLEDGMENTS}

We thank the Geosciences and Biosciences Division, Office of the Basic Energy Sciences, Office of Science, and U.S. Department of Energy for supporting this work under grant DEFG02-86ER13622-A000. We also thank Wei Zhong for her help with XPS.

\section{REFERENCES}

1. C. Robert, C.M. Thomas, Chem. Soc. Rev. 42 (2013) 9392-9402.

2. M.J. Climent, A. Corma, S. Iborra, RSC Adv. 2 (2012) 16-58.

3. M.J. Climent, A. Corma, S. Iborra, Chem. Rev. 111 (2011) 1072-1133.

4. M.J. Climent, A. Corma, S. Iborra, M.J. Sabater, ACS Catal. 4 (2014) 870-891.

5. J.M. Pérez, R. Cano, M. Yus, D.J. Ramón, Eur. J. Org. Chem. 24 (2012) 4548-4554.

6. R.D. Patil, S. Adimurthy, Adv. Synth. Catal. 353 (2011) 1695-1700.

7. H. Tian, X. Yu, Q. Li, J. Wang, Q. Xu, Adv. Synth. Catal. 354 (2012) 2671-2677.

8. B. Gnanaprakasam, J. Zhang, D. Milstein, Angew. Chem. Int. Ed. 49 (2010) 1468-1471.

9. J. Soule, H. Miyamura, S. Kobayashi, Chem. Commun. 49 (2013) 355-357.

10. R. R. Donthiri, R.D. Patil, S. Adimurthy, Eur. J. Org. Chem. 24 (2012) 4457-4460. 
11. A. Grirrane, A. Corma, H. Garcia, J. Catal. 264 (2009) 138-144.

12. B. Zhu, M. Lazar, B.J. Trewyna, R.J. Angelici, J. Catal. 260 (2008) 1-6.

13. H. Yuan, W. Yoo, H. Miyamura, S. Kobayashi, J. Am. Chem. Soc. 134 (2012) 1397013973.

14. H. Huang, J. Huang, Y. Liu, H. He, Y. Cao, K. Fan, Green Chem., 14 (2012) 930-934.

15. Z. Hu, F.M. Kerton, Org. Biomol. Chem., 10 (2012) 1618-1624.

16. P. Liu, C. Li, E. J.M. Hensen, Chem. Eur. J. 18 (2012) 12122-12129.

17. J. Xu, R. Zhuang, L. Bao, G. Tang, Y. Zhao, Green Chem., 14 (2012) 2384-2387.

18. P.R. Likhar, R. Arundhathi, M.L. Kantam, P.S. Prathima, Eur. J. Org. Chem. 31 (2009) 5383-5389.

19. M.S. Kwon, S. Kim, S. Park, W. Bosco, R.K. Chidrala, J. Park, J. Org. Chem. 74 (2009) 2877-2879.

20. E. Ali, M.R. Naimi-Jamal, M.G. Dekamin, Sci. Iranica 20 (2013) 592-597.

21. K.C. Nicolaou, C.J.N. Mathison, T. Montagnon, Angew. Chem. Int.Ed. 42 (2003) 40774082.

22. A.S. Poyraz, C-H. Kuo, E.Kim, Y. Meng, M.S. Seraji, S.L. Suib, Chem. Mater., 26 (2014) 2803-2813. 
23. M.N. Pahalagedara, M. Samaraweera, S. Dharmarathna, C-H. Kuo, L.R. Pahalagedara, J.A. Gascon, S.L. Suib, J. Phys. Chem. C. 118 (2014) 17801-17809.

24. Q. Yu, H. Huang, R. Chen, P. Wang, H. Yang, M. Gao, X. Peng, Z. Ye, Nanoscale 4 (2012) 2613-2620.

25. B. Liu, Nanoscale 4 (2012) 7194-7198.

26. B. Zhao, P. Liu, H. Zhuang, Z. Jiao, T. Fang, W. Xu, B. Lu, Y. Jiang, J. Mater. Chem. A, 1 (2013) 367-373.

27. H. Xia, G. Yang, J. Mater. Chem., 22 (2012) 18664-18670.

28. L. Pahalagedara, H. Sharma, C-H. Kuo, S. Dharmarathna, A. Joshi, S.L. Suib, A.B. Mhadeshwar, Energy Fuels 26 (2012) 6757-6764.

29. K. Zhu, J. Sun, H. Zhang, J. Liu, Y. Wang, Journal of Natural Gas Chemistry 21 (2012) 215232.

30. M.D. Goodman, K.A. Arpin, A. Mihi, N. Tatsuda, K. Yano, P.V. Braun, Adv.Optical Mater. 1 (2013) 300-304.

31. A. Malak-Polaczyk, C. Vix-Guterl, E. Frackowiak, Energy Fuels 24 (2010) 3346-3351.

32. C-H. Kuo, A.S. Poyraz, L. Jin, Y. Meng, L. Pahalagedara, S. Chen, D.A. Kriz, C. Guild, A. Gudz, S.L. Suib, Green Chem. 16 (2014) 785-791. 
33. M.N. Pahalagedara, L.R. Pahalagedara, C-H. Kuo, S. Dharmarathna, S.L. Suib, Langmuir 30 (2014) 8228-8237.

34. L. Xu, S. Sithambaram, Y. Zhang, C-H. Chen, L. Jin, R. Joesten, S.L. Suib, Chem. Mater. 21 (2009) 1253-1259.

35. S. Sithambaram, R. Kumar, Y. Son, S.L. Suib, J. Catal. 253 (2008) 269-277.

36. B. Mallesham, P. Sudarsanam, G. Raju, B.M. Reddy, Green Chem. 15 (2013) 478-489.

37. S. Kegnaes, J. Mielby, U.V. Mentzel, C. H. Christensen, A. Riisager, Green Chem. 12 (2010) 1437-1441.

38. L. Jiang, L. Jin, H. Tian, X. Yuan, X. Yu, Q. Xu, Chem. Commun. 47 (2011) 10833-10835.

39. B. Chen, J. Li, W. Dai, L. Wang, S. Gao, Green Chem. 16 (2014) 3328-3334.

40. R. Vijaya Kumar, R. Elgamiel, Y. Diamant, A. Gedanken, Langmuir 17 (2001) 1406-1410.

41. L.R. Pahalagedara, A.S. Poyraz, W. Song, C-H. Kuo, M.N. Pahalagedara, Y. Meng, S.L. Suib, Chem. Mater. 26 (2014) 6613-6621.

42. C. Doornkamp, V. Ponec, J. Mol. Catal. A: Chem. 162 (2000) 19-32.

43. H.C. Genuino, Y. Meng, D.T. Horvath, C. Kuo, M.S. Seraji, A.M. Morey, R.L. Joesten, S.L. Suib, Chem. Cat. Chem. 5 (2013) 2306-2317. 
Table 1. Structural parameters of $\mathrm{CuAl}$ MOs.

\begin{tabular}{|c|c|c|c|c|}
\hline Catalyst & $\begin{array}{l}\text { Average crystallite } \\
\text { size }(\mathrm{nm})\end{array}$ & BET SA $\left(\mathrm{m}^{2} / \mathrm{g}\right)$ & $\begin{array}{l}\text { BJH desorption pore } \\
\text { volume }\left(\mathrm{cm}^{3} / \mathrm{g}\right)\end{array}$ & $\begin{array}{c}\text { BJH desorption pore } \\
\text { diameter }(\AA ̊)\end{array}$ \\
\hline CuAl $\mathrm{MO}_{0 \% \mathrm{C}}$ & 27.7 & 14 & .093 & 33 \\
\hline CuAl $\mathrm{MO}_{5 \% \mathrm{C}}$ & 4.1 & 24 & .075 & 37 \\
\hline CuAl $\mathrm{MO}_{10 \% \mathrm{C}}$ & 4.4 & 50 & 0.22 & 38 \\
\hline $\mathrm{CuAl} \mathrm{MO}_{20 \% \mathrm{C}}$ & 1.1 & 161 & 0.27 & 40 \\
\hline
\end{tabular}


Table 2 . Synthesis of imines catalyzed by various $\mathrm{CuAl}$ MO catalysts.

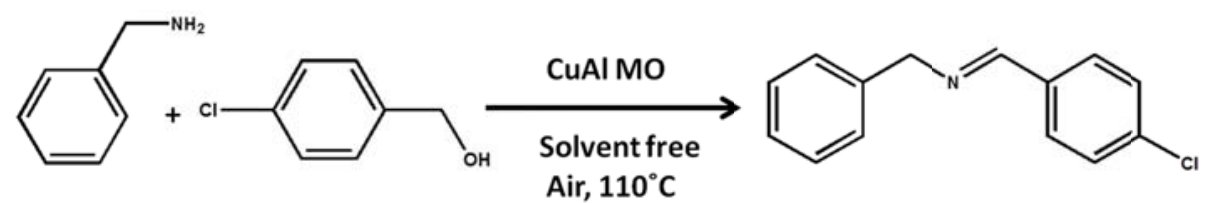

E

2

CuAl $\mathrm{MO}_{5 \% \mathrm{C}}$

110

72

3

CuAl MO $\mathrm{M}_{10 \% \mathrm{C}}$

110

78

4

CuAl $\mathrm{MO}_{20 \% \mathrm{c}}$

110

100

5

CuAl $\mathrm{MO}_{20 \% \mathrm{C}}(6 \mathrm{~h})$

110

95

6

CuAl $\mathrm{MO}_{20 \% \mathrm{C}}$

60

32

7

CuAl $\mathrm{MO}_{20 \% \mathrm{C}}$

80

54

8

CuAl $\mathrm{MO}_{20 \% \mathrm{C}}$

140

40

9

CuAl $\mathrm{MO}_{20 \% \mathrm{C}}{ }^{\mathrm{a}}$

110

15

10

No catalyst

110

Trace

11

Commercial CuO

110

8 
$\mathrm{CuAl}_{2} \mathrm{O}_{4}$

Reaction conditions: 4-Chlorobenzyl alcohol $(1 \mathrm{mmol})$, benzylamine $(1.2 \mathrm{mmol})$, catalyst (50 $\mathrm{mg}) 110^{\circ} \mathrm{C}, 12 \mathrm{~h}$. Conversion and selectivity determined and confirmed by GC-MS. Selectivity was $100 \%$ towards the imine product. ${ }^{a} \mathrm{~N}_{2}$ balloon. 
Table 3. $\mathrm{CuAl} \mathrm{MO}_{20 \% \mathrm{C}}$ catalyzed synthesis of imines from various alcohols and amines. ${ }^{\mathrm{a}}$

Entry Substrate 1


9<smiles>NCc1ccccc1</smiles><smiles>CC(C)O</smiles>

10<smiles>NCc1ccc(Cl)cc1Cl</smiles><smiles>OCc1ccc(Cl)cc1</smiles>

11<smiles>NCc1ccc(Cl)cc1Cl</smiles>

12<smiles>NCc1ccc(Cl)cc1Cl</smiles><smiles>O=Cc1ccc(Cl)cc1</smiles><smiles>CC(C)=NCc1ccccc1</smiles><smiles>Clc1ccc(/C=N/Cc2ccc(Cl)cc2Cl)cc1</smiles>

1 100<smiles>Clc1ccc(/C=N/Cc2ccc(Cl)cc2Cl)cc1</smiles>

88 100<smiles>Clc1ccc(/C=N/Cc2ccc(Cl)cc2Cl)cc1</smiles>

52 100

${ }^{a}$ Reaction conditions: alcohol ( $\left.1 \mathrm{mmol}\right)$, amine $(1.2 \mathrm{mmol})$, [catalyst $(50 \mathrm{mg})$ : except entry $10 \&$ $11], 110^{\circ} \mathrm{C}, 12 \mathrm{~h}$. Conversion and selectivity determined and confirmed by GC-MS. ${ }^{\mathrm{b}}$ The other product was the corresponding aldehyde of the alcohol. 


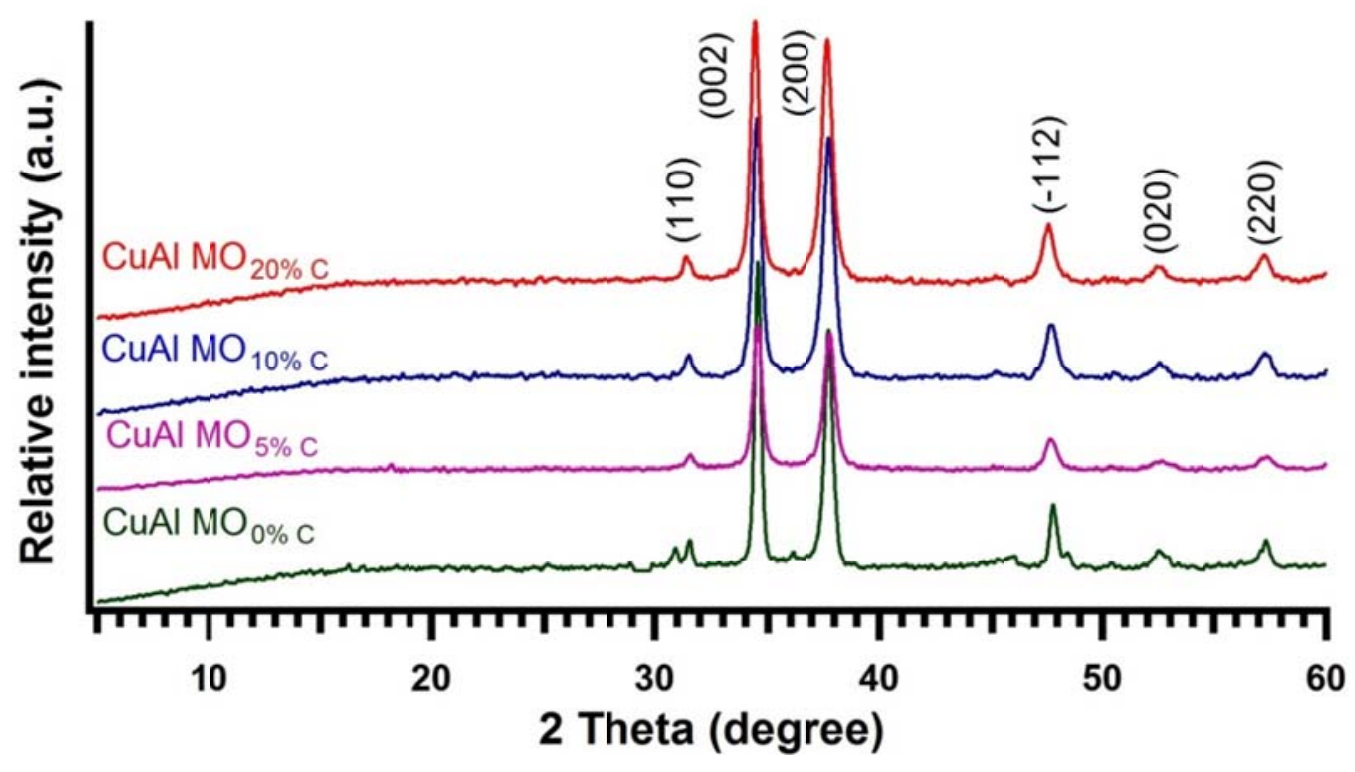

Figure 1. X-ray diffraction patterns of $\mathrm{CuAl}$ MOs synthesized with different amounts of activated carbon.

(a)

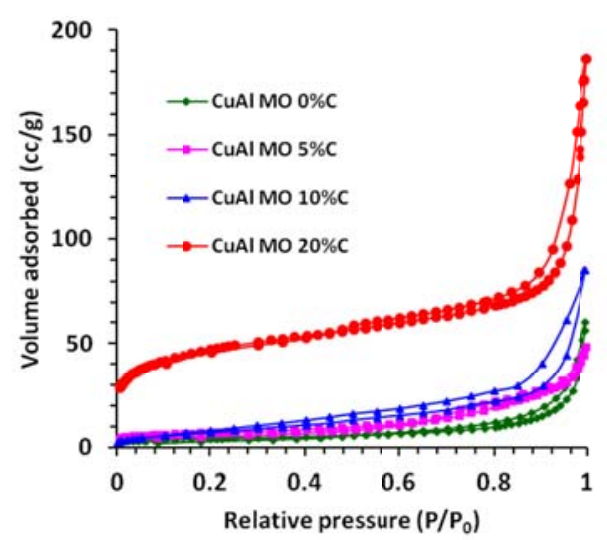

(b)

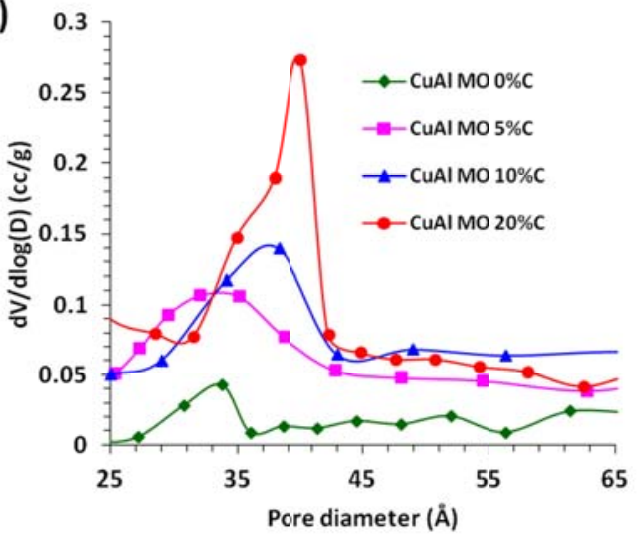

Figure 2. (a) $\mathrm{N}_{2}$ adsorption/desorption isotherms and (b) BJH pore size distribution curves of $\mathrm{CuAl}$ MOs synthesized with different amounts of activated carbon. 

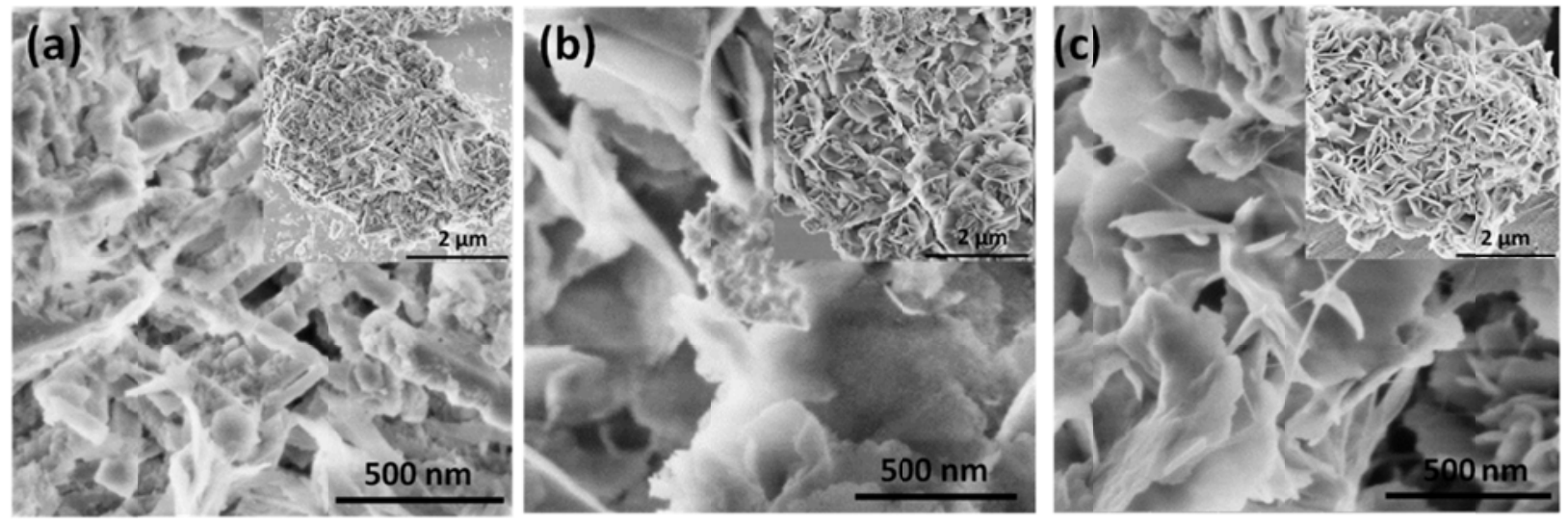

Figure 3. FE-SEM images of $\mathrm{CuAl}$ mixed hydroxide materials synthesized with (a) $0 \%$ activated carbon and (b) $20 \%$ activated carbon and (c) $\mathrm{CuAl} \mathrm{MO}_{20 \% \mathrm{C}}$ catalyst.

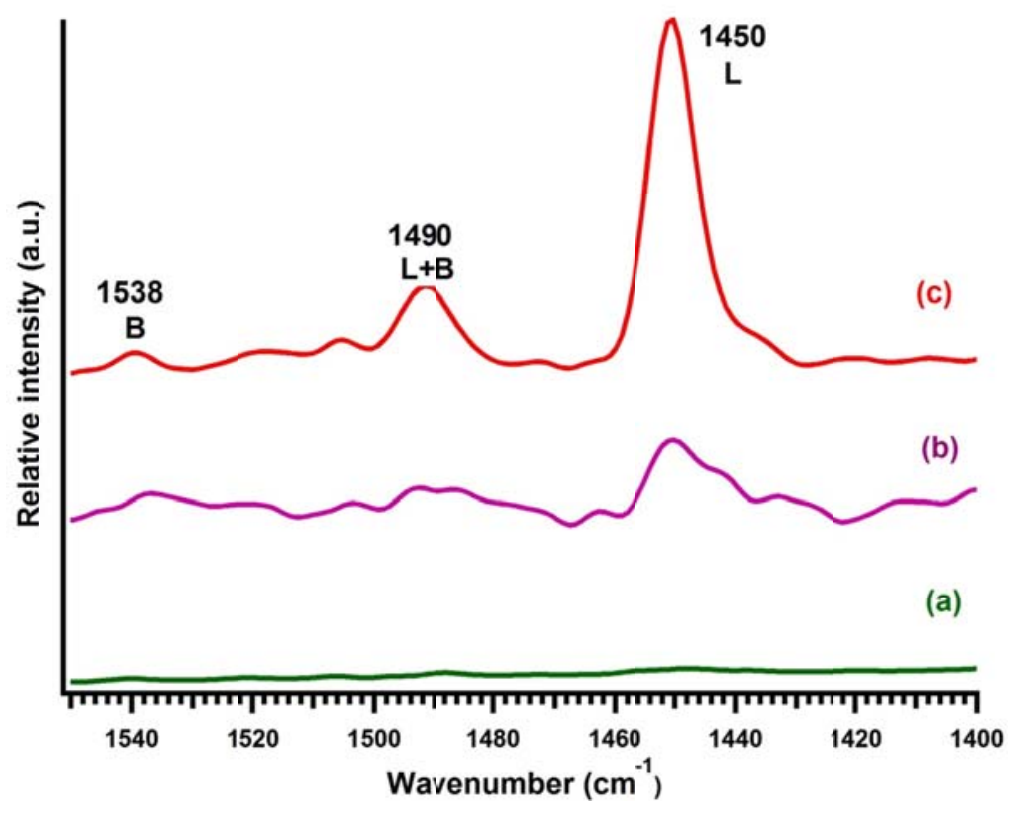

Figure 4. The pyridine adsorption IR spectra of (a) $\mathrm{CuAl} \mathrm{MO}{ }_{0 \% \mathrm{C}}$ (b) $\mathrm{CuAl} \mathrm{MO}_{5 \% \mathrm{C}}$ and (c) $\mathrm{CuAl}$ $\mathrm{MO}_{20 \% \mathrm{C}}$ catalysts. 


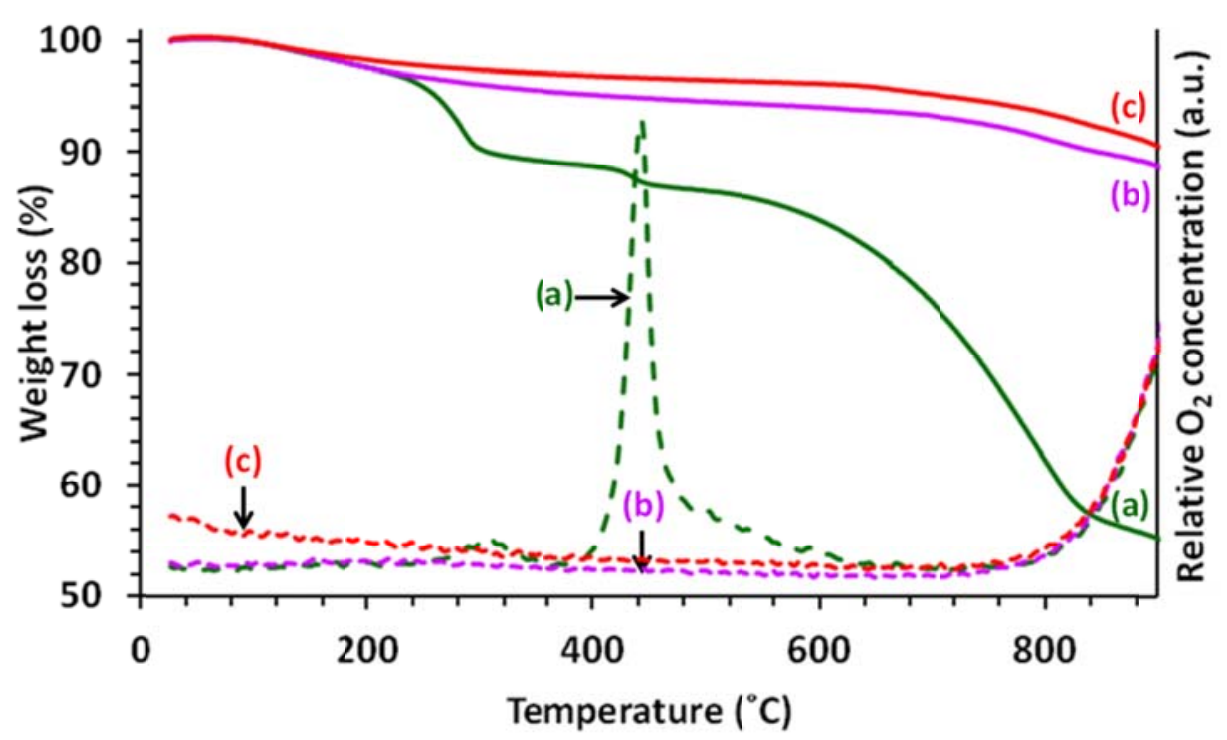

Figure 5. TGA (solid line) and $\mathrm{O}_{2}$ evolution profiles (dash line) of (a) $\mathrm{CuAl} \mathrm{MO}_{0 \% \mathrm{C}}$ (b) $\mathrm{CuAl}$ $\mathrm{MO}_{5 \% \mathrm{C}}$ and (c) $\mathrm{CuAl} \mathrm{MO} \mathrm{M}_{20 \mathrm{C}}$ catalysts. 


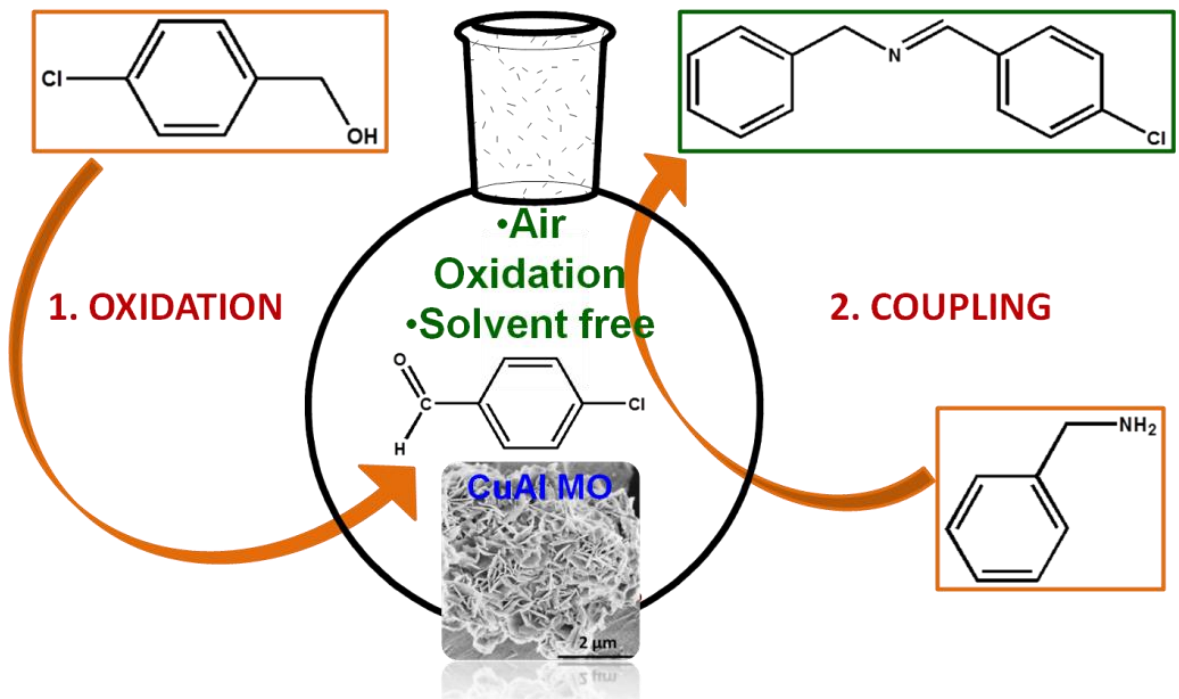

